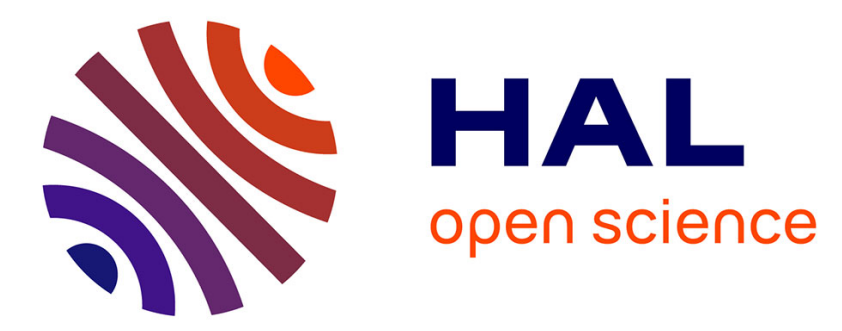

\title{
New insights into the nutritional regulation of gluconeogenesis in carnivorous rainbow trout (Oncorhynchus mykiss): a gene duplication trail.
}

Lucie Marandel, Iban Seiliez, Vincent Veron, Sandrine Skiba-Cassy, Stéphane Panserat

\section{To cite this version:}

Lucie Marandel, Iban Seiliez, Vincent Veron, Sandrine Skiba-Cassy, Stéphane Panserat. New insights into the nutritional regulation of gluconeogenesis in carnivorous rainbow trout (Oncorhynchus mykiss): a gene duplication trail.. Physiological Genomics, 2015, 47 (7), pp.253-263. 10.1152/physiolgenomics.00026.2015 . hal-01901407

\section{HAL Id: hal-01901407 \\ https://hal.science/hal-01901407}

Submitted on 28 May 2020

HAL is a multi-disciplinary open access archive for the deposit and dissemination of scientific research documents, whether they are published or not. The documents may come from teaching and research institutions in France or abroad, or from public or private research centers.
L'archive ouverte pluridisciplinaire HAL, est destinée au dépôt et à la diffusion de documents scientifiques de niveau recherche, publiés ou non, émanant des établissements d'enseignement et de recherche français ou étrangers, des laboratoires publics ou privés.

\section{다(1)(2)}

Distributed under a Creative Commons Attribution - ShareAlikel 4.0 International 


\section{New insights into the nutritional regulation of} 2 gluconeogenesis in carnivorous rainbow trout 3 (Oncorhynchus mykiss): a gene duplication trail

$5 \quad$ Lucie Marandel ${ }^{\S}$, Iban Seiliez, Vincent Véron, Sandrine Skiba-Cassy, Stéphane 6 Panserat

8 Institut National de la Recherche Agronomique (INRA), Nutrition, Metabolism and

9 Aquaculture Unit (UR1067), Saint-Pée-sur-Nivelle F-64310,France

$10{ }^{\S}$ Corresponding author

12 Email addresses:

\section{LM: 1ucie.marandel@st-pee.inra.fr} IS: iban.seiliez@st-pee.inra.fr VV: vincent.veron@st-pee.inra.fr SSC: $\underline{\text { sandrine.skiba@st-pee.inra.fr }}$ SP: stephane.panserat@,st-pee.inra.fr

\section{.} 20 1

Running head : The atypical regulation of gluconeogenesis : a gene duplication trail 5 6 


\section{Abstract}

28 The rainbow trout (Oncorhynchus mykiss) is considered to be a strictly carnivorous fish species that is metabolically adapted for high catabolism of proteins and low utilisation of dietary carbohydrates. This species consequently has a "glucoseintolerant" phenotype manifested by persistent hyperglycaemia when fed a highcarbohydrate diet. Gluconeogenesis in adult fish is also poorly, if ever, regulated by carbohydrates, suggesting that this metabolic pathway is involved in this specific phenotype. In this study, we hypothesised that the fate of duplicated genes after the salmonid-specific $4^{\text {th }}$ whole genome duplication (Ss4R) may have led to adaptive innovation and that their study might provide new elements to enhance our understanding of gluconeogenesis and poor dietary carbohydrates use in this species.

Our evolutionary analysis of gluconeogenic genes revealed that $p c k 1, p c k 2, f b p 1 a$ and g6pca were retained as singletons after Ss4r while g6pcb1, g6pcb2 and $f b p 1 b$ ohnologue pairs were maintained. For all genes, duplication may have led to sub- or neo-functionalisation. Expression profiles suggested that the gluconeogenesis pathway remained active in trout fed a no carbohydrate diet. When trout were fed a high-carbohydrate diet (30\%), most of the gluconeogenic genes were non- or downregulated, except for $g 6 p b c 2$ ohnologues the RNA levels of which were surprisingly increased.

This study demonstrated that Ss4R in trout involved adaptive innovation via gene duplication and via the outcome of the resulting ohnologues. Indeed, maintenance of ohnologuous g6pcb2 pair may contribute in a significant way to the "glucoseintolerant" phenotype of trout and may partially explain its poor use of dietary carbohydrates. 


\section{Keywords}

52 gluconeogenesis, carbohydrates, trout, gene duplication, carnivorism, adaptation

\section{Introduction}

54 The rainbow trout (Oncorhynchus mykiss) is considered to be a strictly 55 carnivorous fish species with nutritional needs linked to this specific dietary regime. 56 Indeed, carnivorous species naturally require a diet consisting of high protein and 57 moderate fat content but with minimal amounts of carbohydrate. The rainbow trout, 58 with other carnivores such as the cat, mink and carnivorous teleosts (for instance 59 European seabass, Dicentrarchus labrax), are thus metabolically adapted for high 60 catabolism of proteins and low utilisation of dietary carbohydrates. They are therefore 61 considered to be a glucose intolerant species due mainly to persistent hyperglycaemia 62 after intake of carbohydrate-enriched meal(s) or glucose tolerance tests (cat $(18,48)$; 63 trout $(1,2,40,50)$; several teleosts, reviewed by Polakof et al., 2012 (41)). Moreover, 64 another adaptive carnivorous trait is a higher rate of hepatic gluconeogenesis $(45,51$, $53,56,59)$ than omnivorous species, allowing them to sustain endogenous glucose

demands, i.e maintenance of normoglycaemia and production of energy using gluconeogenic amino acids and fat rather than dietary carbohydrates $(7,10,57,58$, 61). Probably as a result of no dietary carbohydrate requirements, gluconeogenesis in adult fish is also poorly, if ever, regulated by carbohydrates $(17,20,26,30-32,34)$.

Several studies performed in rainbow trout have shown that biochemical pathways $(22,29,30,37,54)$ and control mechanisms $(8,27,39,41,42)$ of glucose metabolism are conserved (38). Nevertheless, the plasticity of this system differs from one carnivorous species to another. For instance, the differential nutritional regulation of glucokinase (Gck, enzymatic activity and gene expression) across carnivorous species (reviewed by Panserat et al, 2014 (33)) is an indisputable illustration of this 
fact. Indeed, cats have a very low functional Gck with no capacity to be inducible by dietary carbohydrates whereas in rainbow trout both expression and enzymatic activity of Gck are well up-regulated by such a diet. Species thus adapt to carnivorism using differential physiological strategies.

In teleosts, radiation was preceded by three rounds of whole genome duplication (WGD)( teleost-specific 3rd WGD or Ts3R), believed to be involved in the evolution and diversification of teleost fish. An additional round of WGD then occurred in salmonids (Ss4R salmonid-specific $4^{\text {th }}$ WGD, $(3,24)$ ). WGD may represent a major evolutionary event in the study of adaptive mechanisms to carnivorism in rainbow trout. Indeed, after whole genome duplication, several scenarios can occur: the duplicated genes can be lost or fixed and maintained with three distinct outcomes, i.e. neofunctionalisation, subfunctionalisation, and conservation of function (14). Whole genome duplication via gene duplication is thus a source of genetic novelty and can lead to adaptive innovation. In the study of the gluconeogenic pathway, Seiliez et al. $(2011,(49))$ were the first to grasp this feature of rainbow trout by identifying a second gene encoding a glucose-6-phosphatase (called g6pase-2) in EST databases (Expressed Sequence Tag, SIGENAE, http://www.sigenae.org) and showing that both genes displayed differential expression patterns in trout fed a high carbohydrate diet. While the original gluconeogenic pathway in rainbow trout has been well documented by relating measurements of enzyme activity or gene expression gathered in EST databases, this metabolic pathway has never been considered to our knowledge from a genomic point of view, probably due to the unavailability of the genome sequence. Analysis of the recently sequenced rainbow trout genome (3) can now shed new light on processes which contribute to the hyperglycaemia and poor utilisation of dietary carbohydrates in this species. 
102 in rainbow trout, were to characterise i) the evolutionary history of specific hepatic-

103 expressed gluconeogenic genes in teleosts, i.e. cytosolic phosphoenol-pyruvate

104 carboxykinase 1 and mitochondrial phosphoenol-pyruvate carboxykinase 2 (PCK1

105 and PCK2), fructose-1,6-bisphosphatase 1 (FBP1; (13, 55)) and glucose-6-

106 phosphatase 1 (G6PC; (25)) and ii) their expression profile under different nutritional

107 conditions (i.e fasted, non- or high-carbohydrate diet fed, re-fasted).

108 Glossary

109 EST: Expressed Sequence Tag

110 HighCHO: high carbohydrate content diet

111 NADPH: Nicotinamide adenine dinucleotide phosphate

112 NoCHO: diet containing no charbohydrate

113 WGD: whole genome duplication

114 Ss4R: salmonid-specific $4^{\text {th }}$ WGD

115 Ts3R: teleost-specific $3^{\text {rd }}$ WGD

\section{Materials and Methods}

\section{Ethical issues and approval}

118 Investigations were conducted according to the guiding principles for the use and care

119 of laboratory animals and in compliance with French and European regulations on

120 animal welfare (Décret 2001-464, 29 May 2001 and Directive 2010/63/EU,

121 respectively). Fish were killed by concussion/blow to the skull and death was

122 confirmed by exsanguination. No anaesthetic was used to avoid bias in analysis of 123 enzymatic activity. This protocol and the project as a whole were approved by the 124 French National Consultative Ethics Committee. 


\section{Fish diets}

Two experimental diets, i.e., the NoCHO (diet without carbohydrate) and the HighCHO (diet with about 30\% carbohydrates), were prepared in our facilities (INRA, Saint-Pée-sur-Nivelle, France) as pressed pellets. The two diets were isolipidic and isoenergetic (Table 2). Gelatinized starch was included as carbohydrate source, protein was provided by fishmeal and dietary lipid by fish oil and fish meal. Inclusion of carbohydrates $(\sim 30 \%)$ in the HighCHO diet was compensated for by a decreased dietary protein level ( 40\%), which was still above the $37 \%$ protein requirement of rainbow trout $(\mathrm{NRC}, 2011)$. No carbohydrates were added to the NoCHO diet, which contained $\sim 60 \%$ crude protein.

\section{Fish and experimental design}

Juvenile rainbow trout ( $\sim 70 \mathrm{~g}$ body mass) were distributed in six tanks (15 fish per tank) and reared at $17^{\circ} \mathrm{C}$ in the INRA experimental facilities at Saint-Pée-sur-Nivelle, France. After four days of total starvation, two fish per tank were killed. Fish were then fed with either the NoCHO or the HighCHO diet (triplicate tanks per diet) twice a day at $2.5 \%$ live weight for four days and sampled $6 \mathrm{~h}$ after the last meal $(\mathrm{n}=9$ fish per diet, 3 per tank) in order to monitor the expected hyperglycaemic phenotype. Gut content of the sampled animals was systematically checked to confirm that the fish sampled had consumed the diet. The remaining fish were then starved again and killed after four days ( $\mathrm{n}=9$ fish per diet, 3 per tank). Blood was removed from the caudal vein using heparinized syringes and centrifuged (3000 g, $5 \mathrm{~min}$ ). The plasma recovered was immediately frozen and kept at $-20^{\circ} \mathrm{C}$ until analysis. The fresh liver of each fish was dissected, part was used for enzyme activity analysis and the remaining part was immediately frozen in liquid nitrogen and then kept at $-80^{\circ} \mathrm{C}$. 
149

150 The chemical composition of the diets was analysed using the following procedures:

151 1) dry matter was determined after drying at $105^{\circ} \mathrm{C}$ for $24 \mathrm{~h}, 2$ ) protein content

$152(\mathrm{~N} \times 6.25)$ was determined by the Kjeldahl method after acid digestion, 3) fat was

153 determined by petroleum ether extraction (Soxtherm), 4) gross energy was determined

154 in an adiabatic bomb calorimeter (IKA, Heitersheim Gribheimer, Germany), 5) ash

155 content was determined by incinerating the samples in a muffle furnace at $600^{\circ} \mathrm{C}$ for

156 6h, and 6) starch content was measured by an enzymatic method (InVivo Labs,

157 France). Plasma glucose levels were determined by using a commercial kit

158 (Biomérieux, Marcy l'Etoile, France) adapted to a microplate format according to the

159 manufacturer's instructions.

\section{In silico analysis}

161 Orthologous Pck1, Pck2, Fbp1 and G6pc genes in the rainbow trout genome (3) were

162 collected from the SIGENAE database (http://www.sigenae.org) using the BLAST

163 tool (all accession numbers are given in brackets in Figure 1). Sequences from other

164 species were collected from the Ensembl Genome database (Ensembl release 77 -

165 October 2014, http://www.ensembl.org) or Genbank. The Genomicus software

166 program, version $01.01 \quad$ (http://www.genomicus.biologie.ens.fr/genomicus-trout-

$16701.01 /$ cgi-bin/search.pl) was used to confirm their identities by establishing syntenic 168 analysis (Fig.2).

169 Phylogenetic analyses were performed using the MEGA package version 5 software

170 (52), as previously described (11). The phylogenetic trees, based on full-length amino

171 acid deduced sequences, were built using the Neighbor-Joining (NJ) method and

172 confirmed by the Minimum evolution method (data not shown). The reliability of the

173 inferred trees was estimated using the bootstrap method with 1,000 replications.

174 Branchiostoma floridae Pck (Genbank accession XP_002593974), Oikopleura dioica 
175 Fbp (Genbank accession CBY10016) and Latimeria chalumnae G6pc (Ensembl

176 accession ENSLACG00000022601) protein sequences were used to root trees for Pck

177 (Fig.1A), Fbp1 (Fig.1B) and G6pc (Fig.1C) phylogenetic analysis, respectively.

178 New gene annotations were allocated according to ZFIN Nomenclature guidelines

179 (http://zfin.org/).

180 Percentage Identity Matrices established among paralogous teleost sequences (Table

181 1) were calculated with Clustal 2.1 using the MUSCLE interface (9).

182 Total RNA extraction and cDNA synthesis

183 Relative hepatic gene expression was determined by quantitative real-time RT-PCR.

184 Samples were homogenised using Precellys ${ }^{\circledR 2} 24$ (Bertin Technologies, Montigny-le-

185 Bretonneux, France) in $2 \mathrm{~mL}$ tubes containing Trizol reagent (Invitro-gen, Carlsbad,

186 CA, USA) and 2.8 millimiter ceramic beads, 2 x 10 seconds, separated by 15 seconds

187 off, at 5,000 rpm. The extraction of total RNA was then performed according to the

188 manufacturer's instructions. Total RNA $(1 \mu \mathrm{g})$ was used for cDNA synthesis. The

189 Super-Script III RNAse H-Reverse transcriptase kit (Invitro-gen) was used with

190 random primers (Promega, Charbonniéres,France) to synthesize cDNA ( $\mathrm{n}=9$ for each

191 treatment).

192 Real time RT-PCR

193 The primer sequences used in real-time RT-PCR assays are listed in Table 3. For gene

194 targets that had not previously been validated, primers were tested on a pool of cDNA

195 and amplified products were systematically sequenced. The protocol conditions for

196 real-time RT-PCR have been published previously (49). For real-time RT-PCR

197 assays, the Roche Lightcycler 480 system was used (Roche Diagnostics, Neuilly-sur-

198 Seine, France). The assays were performed using a reaction mix of $6 \mu$ per sample,

199 each of which contained $2 \mu \mathrm{l}$ of diluted cDNA template, $0.12 \mu \mathrm{l}$ of each primer (10 
$\mu \mathrm{M}), 3 \mu 1$ Light Cycler $480 \mathrm{SYBR}{ }^{\circledR}$ Green I Master mix and $0.76 \mu 1$ DNAse/RNAse

201 free water (5 Prime GmbH, Hamburg, Germany). The PCR protocol was initiated at $20295^{\circ} \mathrm{C}$ for $10 \mathrm{~min}$ for initial denaturation of the cDNA and hot-start Taq-polymerase 203 activation, followed by 45 cycles of a two-step amplification programme (15s at $20495^{\circ} \mathrm{C} ; 40 \mathrm{~s}$ at $60^{\circ} \mathrm{C}$ ). Melting curves were systematically monitored (temperature 205 gradient $1.1^{\circ} \mathrm{C} / 10 \mathrm{~s}$ from $65-94^{\circ} \mathrm{C}$ ) at the end of the last amplification cycle to 206 confirm the specificity of the amplification reaction. Each PCR assay included 207 replicate samples (duplicate of reverse transcription and PCR amplification, 208 respectively) and negative controls (reverse transcriptase- and cDNA template-free 209 samples, respectively). For the expression analysis, relative quantification of target 210 gene expression was performed using the $\Delta \mathrm{CT}$ method (36). The relative gene 211 expression of Rps16 (ribosomal protein 40S S6, (28)) was used for the normalization 212 of measured mRNA as its relative expression did not significantly change over 213 sampling time (data not shown). In all cases, PCR efficiency was measured by the 214 slope of a standard curve using serial dilutions of cDNA. In all cases, PCR efficiency 215 values ranged between 1.89 and 2.0.

\section{Enzyme activity}

217 Fresh livers used to assess enzyme activity were ground in 8 volumes of ice cold 218 buffer at $\mathrm{pH} 7.4$ (50mmol/1 TRIS, 5mmol/1 EDTA, $2 \mathrm{mmol} / 1 \mathrm{DTT}$ and a protease 219 inhibitor cocktail (Sigma, St Louis, MO; P2714) and centrifuged for 10 min at 900g at $2204{ }^{\circ} \mathrm{C}$. Assays were performed from the recovered supernatants for Gck and Fbp 221 activity. For G6pc, one minute of sonic disruption was then applied to the 222 homogenized samples kept on ice, then samples were centrifuged for $20 \mathrm{~min}$ at $22310,000 \mathrm{~g}$ at $4^{\circ} \mathrm{C}$ and supernatants were used for enzyme assays. For Pck1 and Pck2 224 activity, in order to separate the cytosolic and the mitochondrial fractions, additional 
225 centrifugation (20 minutes, $10,000 \mathrm{~g}$ at $4^{\circ} \mathrm{C}$ ) was performed on supernatants obtained

226 after first centrifugation at $900 \mathrm{~g}$. After the second centrifugation, supernatants were

227 kept for cytosolic Pck1 assay. The pellets containing the mitochondrial fraction were

228 recovered in $500 \mu \mathrm{L}$ of ice cold buffer at $\mathrm{pH} 7.4$ and sonicated as described above. The

229 enzymes assayed were: high Km Hexokinase (Gck), as described by Panserat et al.

230 (2000, [25]), G6Pase from Alegre et al. (1988, [62]), Pck following protocol of

231 Kirchner et al. (2003, [63]) and Fbp, described by Tranulis et al. (1996, [64]). The

232 enzyme activity was measured in duplicate at $30^{\circ} \mathrm{C}$ following the variation of

233 absorbance of NADPH (Nicotinamide adenine dinucleotide phosphate) at $340 \mathrm{~nm}$. The

234 reactions were started by the addition of the specific substrate; a Power Wave X

235 (BioTek Instrument, Inc.) plate reader was used. Water was used as a blank for each

236 sample. One unit of enzyme activity was defined as the amount of enzyme that

237 catalysed the hydrolysis of $1 \mu \mathrm{mol}$ of substrate per minute at $30^{\circ} \mathrm{C}$. Enzyme activity

238 was expressed per milligram of soluble protein. Protein concentrations were measured

239 in triplicate according to Bradford (1976, [65]), using a protein assay kit (Bio-Rad,

240 München, Germany) with bovine serum albumin as a standard.

\section{Statistical analysis}

242 Normality of distributions was assessed using the Shapiro-Wilk test. Data were then

243 analyzed by a Kruskal-Wallis non-parametric test following by a Tukey test as a post-

244 hoc analysis. Data were analysed using the R software (v.3.1.0)/R Commander

245 package.

\section{Results}

\section{In silico analysis of gluconeogenic genes}

248 By analysing assembly of the rainbow trout genome (3) we identified for the first time

249 several genes sharing high sequence homology with the gluconeogenic zebrafish 
250 (Danio rerio) and human (Homo sapiens) orthologues: two were related to PCK, three

251 to FBP1, and five to G6PC. A phylogenetic analysis, using full-length vertebrate

252 protein sequences, and a syntenic analysis were then performed to clarify the identity

253 of these rainbow trout sequences.

254 Our Pck phylogenetic analysis showed that one of the rainbow trout sequences

255 identified (GSONMG00082468001) was grouped with pck1 vertebrate orthologues

256 while the other (GSONMG00059643001) was grouped with pck2 vertebrate

257 orthologues (Fig.1A). We also found that both rainbow trout genes were located in

258 two distinct syntenic groups, ccndbp1-psme1 for GSONMG00082468001 and dcaf11-

259 psme1 for GSONMG00059643001, conserved around pck1 and pck2 loci,

260 respectively, in zebrafish (data not shown). In addition, amino acid sequence identity

261 analysis confirmed that the deduced protein sequence from the

262 GSONMG00082468001 gene shared higher percentage identity with human and

263 zebrafish Pck1 sequences than with Pck2 sequences, while the opposite was true for

264 the amino acid sequence deduced from the GSONMG00059643001 gene (Table 1-A).

265 On studying FBP1 related rainbow trout genes, we showed that two of the

266 three genes identified were co-orthologous to the $f b p 1 b$ gene in zebrafish (Fig.1B).

267 We therefore arbitrarily annotated these genes fbp1b1 (GSONMT00063051001) and

268 fbp1b2 (GSONMT00015701001). Fbp1b1 and Fbp1b2 deduced amino acid sequences

269 were highly conserved (more than 97\% identity) and shared approximately 90\%

270 identity with zebrafish Fbp1b (Table 1-B). The size of the scaffold bearing the third

271 rainbow trout FBP1-related sequence (GSONMG00001932001) was not sufficient to

272 cover the whole gene length. The length of the deduced amino acid sequence was

273 therefore not appropriate for inclusion in the phylogenetic analysis. However, this

274 truncated trout sequence was submitted to a BLAST search against several sequenced 
275 teleost genomes (zebrafish, medaka (Oryzias latipes), fugu (Takifugu rubripes) and

276 tetraodon (Tetraodon nigroviridis)) available in the Ensembl database. In all species,

277 the hit with the highest score matched the fbp1a gene (data not shown). Finally, no

278 informative syntenic conservation was found around $f b p 1 a$ or around $f b p 1 b 2$ because

279 of the small size of the scaffolds. Nevertheless, $f b p 1 b 1$, borne by a larger scaffold,

280 was located in the gas1-C9-dab2-thsb4b syntenic group conserved in the zebrafish,

281 medaka, stickleback (Gasterosteus aculeatus), tetraodon and fugu around the $f b p 1 b$

282 gene (data not shown).

283 Our phylogenetic analysis for $G 6 p c$-related genes revealed that one rainbow 284 trout sequence was orthologous to the zebrafish gene annotated g6pca.1 285 (ENSDARP00000116534) in Ensembl (release 77) while the others grouped pairwise 286 with zebrafish genes annotated g6pca.2 (ENSDARP00000086301) and g6pcb 287 (ENSDARP00000128434), respectively. The typology of the phylogenetic tree 288 indicated that the initial annotation of co-orthologous G6pc genes in zebrafish was 289 inaccurate. Indeed the rooting of the branches inside the teleost sub-tree was more in 290 favour of an initial duplication of the G6pc gene into $g 6 p c a$ and $g 6 p c b$ before or 291 around teleost radiation, followed by a second duplication of at least $g 6 p c b$ giving rise 292 to $g 6 p c b 1$ and $g 6 p c b 2$ genes. We therefore re-annotated zebrafish co-orthologous 293 G6pc genes in our phylogenetic and syntenic analysis (g6pca as a replacement for 294 g6pca.1, g6pcb1 for g6pca.2, and g6pcb2 for g6pcb) (Fig.1C). Moreover, the matrix 295 protein identity (Table 1-C) confirmed that, except for one G6pca 296 (GSONMG00076843001), other rainbow trout G6pc amino acid sequences shared 297 pairwise more than $90 \%$ identity, suggesting that duplicated g6pcb1 and duplicated 298 g6pcb2 genes were retained after Ss4R (3) in the rainbow trout genome as g6pcb1.a 299 (GSONMG00076841001), g6pcb1.b (GSONMG00066036001), g6pcb2.a 
300 (GSONMG00013076001) and g6pacb2.b (GSONMG00014864001). Finally, our

301 syntenic analysis (Fig.2) showed that G6pc in the human and the mouse was located

302 in the wnk4-ccdc56-aoc2-aoc3-aards1-nbr1-tmem106a-arl4d-etv4-meox1 syntenic

303 group. Interestingly, syntenic conservation of nbr1-tmem106a-arl4d was found with

304 all chromosomal regions of teleosts (zebrafish, trout, stickleback (Gasterosteus

305 aculeatus), fugu and tetraodon) which carried the duplicated copies of $g 6 p c$ (except

306 around $g 6 p c b 2$ in zebrafish where the syntenic group was only partially conserved).

307 Similarly, the etv4-meox1 group was found to be specifically syntenic with the $g 6 p c a-$

$308 g 6 p c b 1$ group, while $a o c 2$ was only syntenic with $g 6 p c b 2$ genes, thus confirming the

309 identity of such paralogous genes.

310 An expected phenotype confirmed by persistent post-prandial hyperglycaemia 311 and up-regulation of gck genes after a high carbohydrate content diet

312 Our experimental conditions and diets were designed to arrive at a previously

313 described (49) hyperglycaemic phenotype characterised by a steep rise in plasma

314 glucose concentration and a dramatic increase in glucokinase (gck) mRNA level and 315 enzyme activity with a high carbohydrate diet. The carbohydrate content of the 316 HighCHO diet $(30 \%)$ is higher than those usually used in rich-carbohydrate called 317 diets $(<20 \%$ carbohydrates) for long term nutrition but was chosen in order to 318 dramatically induce such a phenotype. We therefore monitored glycaemia and 319 glucokinase mRNA level and enzyme acitivity.

320 The plasmatic glucose analysis showed that plasma glucose levels were significantly 321 higher after a high carbohydrate diet (HighCHO, Fig.3A) than in fasted trout (i.e. 322 Fasted or Refasted, Fig.3A) or trout fed the NoCHO diet which displayed 323 normoglycaemia $(\sim 0.8 \mathrm{~g} / \mathrm{L})$.

324 As for gluconeogenic genes, we performed an in silico analysis in order to elucidate 325 the gck evolutionary history. We thus identified two sequences in the rainbow trout 
326 genome sharing high homology with the zebrafish gck gene. These two genes were

327 grouped together in the teleost gck phylogenetic sub-tree (Fig.4) as co-orthogues to

328 teleost and tetrapod gck genes. As no duplication of gck in other sequenced teleost

329 genomes was found, we concluded that duplication of gck in rainbow trout occurred

330 before or around the Ss4R, giving rise to gcka (GSONMG00033781001) and gckb

331 (GSONMG00012878001) in this species. Compared with fasted trout and fish fed the

332 NoCHO diet, both gcka and gckb mRNA levels increased dramatically in fish fed the

333 high carbohydrate diet (Fig.3B). The overall Gck activity followed the same trend

334 (Fig.3C), confirming that Gck enzyme activity is a strong indicator of dietary

335 carbohydrate intake.

336 Taken together, these results confirmed the physiological effects of a high

337 carbohydrate content diet in trout expected with this study design, and as previously

338 described (49).

339 Expression analysis of gluconeogenic genes

340 Analysis of gene expression revealed that, although the pck1 mRNA level was not

341 clearly statistically affected by the nutritional status, it was higher in trout fed the

342 NoCHO diet than in trout fed the HighCHO diet (Fig.5A). The mRNA level of pck2

343 (Fig.5A) was constant whatever the experimental condition. No change in Pck1 or

344 Pck2 enzyme activity was noted (Fig.5D-a and 5D-b). As previously described (19),

345 we found that overall Pck activity in the liver comprised approximately one third

346 cytosolic activity (Pck1) and two thirds mitochondrial activity (Pck2) (Fig.5D-a and

347 5D-b).

348 As for $p c k 2$, fbp1a mRNA level remained stable, irrespective of the nutritional status

349 (Fig.5B). In contrast to $f b p 1 b 2$, the $f b p 1 b 1$ mRNA level increased in trout fed the

350 NoCHO diet compared to fasted animals (Fig. 5B). However, intake of the HighCHO 
351 diet caused a decrease in both $f b p 1 b 1$ and $f b p 1 b 2$ paralogue mRNA levels (Fig.5B).

352 The overall Fbp activity (Fig.5D-c) followed the same trend as $f b p 1 b 1$ and $f b p 1 b 2$

353 mRNA levels, with a significant decrease in trout fed the HighCHO diet, but did not

354 follow the increase in $f b p 1 b 1$ mRNA level in trout fed the NoCHO diet.

355 The mRNA level of g6pca (Fig.5C) remained unchanged whatever the nutritional

356 status in trout fed the NoCHO diet while it decreased in trout fed the HighCHO diet

357 and in re-fasted fish fed the latter diet. The $g 6 p c b 1 . b$ mRNA level followed almost the

358 same pattern as g6pca whereas the paralogous g6pcb1.a gene displayed a decrease in

359 mRNA level in trout fed the NoCHO diet, with the same fold change as that observed

360 in trout fed the HighCHO diet (Fig.5C). In striking contrast to all other co-

361 orthologous G6pc genes, the mRNA level of both g6pcb2 paralogues increased in fed

362 trout compared to fasted or re-fasted fish, and to a greater extent when trout were fed

363 the HighCHO diet. Also, the overall G6pc enzyme activity remained unchanged in

364 fasted and fed trout but decreased in re-fasted trout (Fig.5D-d).

365

366

367

368

369

370

371

372

373

374

375

\section{Discussion}

The rapidly increasing number of whole genomes sequenced in model and non-model organisms in the last decade $(3,4,60)$ makes us seriously consider the DNA sequence information to be a powerful tool for unravelling the mechanisms of environmental adaptation. In this context, the outcome of duplicated genes arising through Ss4R in rainbow trout can lead to adaptive innovation (47), depending on whether they are lost or fixed and maintained (14). Elucidating the evolutionary history of such genes and studying their expression patterns may help to reveal new molecular underpinnings involved in adaptive behaviour in rainbow trout. This approach is of particular interest when considering the adaptation of rainbow trout to 
376 carnivorism as this has never previously been explored from a genomic point of view.

377 The present study therefore focused on genes encoding key gluconeogenic enzymes in

378 the liver, the atypical nutritional regulation of the gluconeogenesis pathway being one

379 trail to explain the "glucose-intolerant" phenotype of this carnivorous species.

\section{In silico analysis of the recently sequenced rainbow trout genome revealed the conservation of several duplicated gluconeogenic genes}

The first critical step in elucidating the evolutionary history of gluconeogenic genes was to identify accurately the orthologous genes of mammalian Pck1, Pck2, G6pc and Fbp1 genes in the newly sequenced rainbow trout genome (3). Using phylogenetic and syntenic analyses we identified for the first time a pck1 gene in the rainbow trout genome which was orthologous to the cytosolic Pck1. Our results also confirmed that the pck gene previously sequenced in rainbow trout by Panserat et al. (2001, (31)) was orthologous to the mitochondrial Pck2 gene in other species. For Fbp1, we demonstrated that a duplication of the gene occurred before or around teleost radiation, giving rise to Fbp1a and Fbp1b in teleosts probably as a consequence of the teleost-specific $3^{\text {rd }}$ WGD (Ts3R). After 4SsR, fbp1a was retained as a singleton in the rainbow trout genome while the $f b p 1 b$ ohnologous gene pair (paralogues formed by a WGD event, (3)) consisting of $f b p 1 b 1$ and $f b p 1 b 2$ was preserved. We finally clarified the complex evolutionary history of G6pc (summarised in Fig.6), showing that a duplication of this gene occurred before or around teleost radiation, giving rise to $g 6 p c a$ and $g 6 p c b$ in the ancestral teleost genome. The presence of both $g 6 p c b 1$ and g6pcb2 in the genome of a cypriniform (zebrafish) and a salmonidae (rainbow trout), but only g6pcb1 in Percomorph genomes (medaka, stickleback, fugu and tetraodon), was then in favour of an additional duplication of $g 6 p c b$, at least in the genome of the common ancestor of the Euteleost, Salmonidae and Ostariophys, followed by a loss of g6pcb2 in the 
402 Percomorph ancestor. Analysis of the rainbow trout genome indicated that g6pca was

403 retained as a singleton whereas both ohnologous gene pairs g6pcb1.a-g6pcb1.b and

$404 g 6 p c b 2 . a-g 6 p c b 2 . b$ remained whole after Ss4R. The evolutionary history of

405 gluconeogenic genes confirmed that genes retained as 2R (two rounds of WGD

406 occurring at the base of vertebrates) and Ts3R ohnologues were more likely to have

407 been retained in duplicated copies after Ss4R in rainbow trout (for instance $g 6 p c b$ and

$408 f b p 1 b$, in contrast to $p c k 1$ or $p c k 2$ that were retained as singletons after Ts3R (47)) as

409 demonstrated by Berthelot et al. (2014, (3)). These authors also suggested that WGD

410 involved the loss of one gene copy of ohnologous gene pairs by gene fractionation

411 (loss of functioning DNA sequence, (23)). This process may be the origin of the loss

412 of one $p c k 1, p c k 2, g 6 p c a$ and $f b p 1 a$ ohnologue in rainbow trout after Ss4R.

413 Overall analysis of hepatic expression profiles of gluconeogenic genes

414 suggested sub- or neo-functionalisation of ohnologous genes after Ss4R

415 An overall analysis of expression profiles of the previously described

416 gluconeogenic genes revealed that both genes of each identified ohnologue pair (i.e.,

$417 f b p 1 b 1 / f b p 1 b 2, \quad g 6 p c b 1 . a / g 6 p c b 1 . b$ and $g 6 p c b 2 . a / g 6 p c b 2 . b)$ displayed similar

418 expression patterns, indicating that they belonged to the HC ("high correlation")

419 group defined by Berthelot et al. (2014, (3)). Moreover, these convergent expression

420 patterns were associated with a high percentage of identity of the ohnologue coding

421 region (fbp1b1/fbp1b2, 93.6\%; g6pcb1.a/g6pcb1.b,92.4\% and g6pcb2.a/g6pcb2.b,

$42296.4 \%$ ) suggesting that these sequences were submitted to a high selective pressure, as

423 proposed by Berthelot et al. (2014, (3)). From a paralogous genes point of view, our

424 results showed that $g 6 p c b$ duplication may have led to sub- or neo-functionalisation

425 because $g 6 p c b 1$ ohnologues and $g 6 p c b 2$ ohnologues displayed opposite expression

426 profiles. Nonetheless, since g6pcb2 expression has to our knowledge never been

427 studied in other species (especially not in zebrafish), we cannot conclude that this sub- 
428 or neo-functionalisation occurred only in rainbow trout nor whether it occurred before

429 salmonid radiation. Similarly, $f b p 1$ duplication was probably followed by sub- or neo-

430 functionalisation of $f b p 1 a$ and $f b p 1 b$ ohnologues which probably still occurred after

431 Ts3R. Indeed, whole mount in situ hybridisation data available for zebrafish embryos

432 demonstrates that $f b p 1 a$ mRNA is more related to lens whereas $f b p 1 b$ mRNA is

433 located, amongst other organs, in the liver and in the gut $(5,44)$. Finally, the sub-

434 functionalisation of $p c k 1$ and pck2 highlighted by our results has long been suggested $435(15,16)$.

436 Expression analysis of hepatic gluconeogenic genes in trout fed with or 437 without carbohydrates revealed differential paralogous profiles

438 On considering the different nutritional conditions tested, analyses of the

439 expression of the duplicated gluconeogenic genes revealed that all genes were 440 regulated by nutritional status except pck2 and $f b p 1 a$, the mRNA levels of which 441 remained stable whatever the nutritional status. Our results showed that none of the 442 genes encoding key gluconeogenic enzymes (except g6pcb1.a) were down-regulated 443 in trout fed the NoCHO diet. Indeed, compared to fasting pck1, fbp1b2, g6pca and 444 g6pcb1.b were not regulated whereas $f b p 1 b 1, g 6 p c b 2 . a$ and g6pcb2.b were up445 regulated. These expression data, combined with the maintenance of gluconeogenic 446 enzyme activity, suggested that the gluconeogenesis pathway remained active under 447 NoCHO nutrition according to the need for endogenous glucose production to sustain 448 maintenance of normoglycaemia due to the dietary habits and physiology of 449 carnivorous species $(7,10,57,58,61)$. Furthermore, this is consistent with previous 450 in vivo and in vitro studies showing that the gluconeogenesis flux is never turned off 451 in fed carnivorous teleosts $(35,56)$. Moreover, when trout were submitted to a re452 fasting period we showed that mRNA levels for most of the genes ( $p c k 1, f b p 1 b 1$, $453 f b p 1 b 2, g 6 p c a$ and $g 6 p c b 1 b$ ) were maintained at the same levels as in fed trout. 
454 By contrast, the HighCHO diet led to the down-regulation of most of the 455 gluconeogenic genes (pck1, fbp1b1, fbp1b2, g6pca, g6pcb1.a and g6pcb1.b), 456 suggesting that, as in mammals, dietary carbohydrates are involved in the inhibition of 457 expression of gluconeogenic genes. In addition, dietary carbohydrates seemed to 458 down-regulate overall Fbp1 enzyme activity. These findings suggested that the 459 potential mechanism to minimize gluconeogenic flux in the presence of dietary 460 carbohydrates exists in the trout. However, and surprisingly, mRNA levels of $g 6 p c b 2$ 461 orthologues dramatically increased in trout fed the HighCHO diet in contrast to other 462 G6pc paralogues. Indeed, the expression profiles of $g 6 p c b 2$ ohnologues mimicked 463 those of gck ohnologues and might in part be responsible for the poor regulation of 464 the gluconeogenesis pathway. Such an expression profile of G6pc encoding genes 465 under high carbohydrate nutrition in rainbow trout has never previously been 466 described, as duplicated $g 6 p c b 2$ genes had not been identified before. Indeed, we 467 found that primers used in previous studies amplified only g6pca (e.g., primers named 468 "G6Pase" in (30) and (20) or "g6pase 2" in (49) and (12)) and a conserved region 469 between g6pcb1 ohnologues (primers named "g6pase 1" in (49) and (12)). In 470 addition, it can be hypothesised that the "glucose-intolerant" phenotype in rainbow 471 trout was accentuated by the increased $g 6 p c b 2$ gene dosage due to the fixation of both 472 ohnologues in its genome $(21,43)$. This gene dosage may explain how overall G6pc 473 enzyme activity remained stable in trout fed the HighCHO diet while the mRNA level 474 of three orthologous G6pc genes decreased (g6pca, g6pcb1.a and g6pcb1.b) 475 compared to trout fed the NoCHO diet. The down-regulation of overall G6pc enzyme 476 activity in re-fasted trout also supports this hypothesis as $g 6 p c b 2$ mRNA levels 477 decreased dramatically under re-fasting. 
478 Altogether, our results suggest that the atypical expression profiles of $g 6 p c b 2$

479 ohnologues, and probably the resulting enzyme activity, may contribute significantly

480 to the non-inhibition of the last step of gluconeogenic flux and to the enrichment of 481 plasma glucose via futile glucose/glucose-6-phosphate cycling (56) in trout fed a 482 carbohydrate-enriched diet. Interestingly, in Type 2 diabetes under hyperglycaemia 483 and in conditions where endogenous glucose production is minimized, a significant 484 glucose/glucose-6-phosphate activity cycle occurs (46) that is mediated in part by 485 increased G6pase flux (6) but largely dependent on glucokinase activity. The lesson 486 learned from trout naturally exhibiting this phenotype may thus cast light on defects 487 in metabolism that contribute to diabetes.

\section{Conclusions}

489 The results of this study demonstrated the importance of considering the additional 490 round of WGD occurring in teleosts and in salmonids as major evolutionary events 491 which can lead to adaptive innovation via gene duplication. Indeed, under the 492 HighCHO diet the absence of $p c k 2$ and $f b p 1 a$ down-regulation and, more surprisingly, 493 the increase in mRNA levels of both $g 6 p c b 2$ ohnologues are new elements to enhance 494 our understanding of the poor use of dietary carbohydrates in rainbow trout. Further 495 studies such as gene knock-out assays are now needed to evaluate the involvement of 496 these duplicated genes in the carnivorous "glucose-intolerant" phenotype of rainbow 497 trout.

\section{Acknowledgements}

499 We thank M.Cluzeaud, A. Herman, E. Plagnes-Juan and A. Surget for technical 500 assistance in the laboratory. We also thank P. Aguirre for animal care and preparation 501 of diets. We also thank I. Geurden and C. Burel for their enlightened advice for the 502 establishment of diet formula. 
504 This work benefited from the financial support of the INRA PHASE Department.

\section{Disclosures}

506 The authors declare that there are no conflicts of interests.

507

508

509

510

511

512

513

514

515

516

517

518

519

520

521

522

523

524

525

526

527

528

529

530

531

532

533

534

535

536

537

538

539

540

541

542

\section{Authors' contributions}

L.M and S.P designed the study. L.M managed the study, performed in silico,

expression and statistical analysis, and wrote the manuscript. V.V performed enzyme

activity analysis. I.S., S. S.-C., V.V. and S. P. contributed to the manuscript

correction.

\section{References}

1. Bergot F. Effects of dietary carbohydrates and of their mode of distribution on glycaemia in rainbow trout (Salmo gairdneri richardson). Comp Biochem Physiol A Mol Integr Physiol 64: 543-547, 1979.

2. Bergot F. [Specific problems posed by carbohydrate utilization in the rainbow trout]. Ann Nutr Aliment 33: 247-257, 1979.

3. Berthelot C, Brunet F, Chalopin D, Juanchich A, Bernard M, Noel B, Bento P, Da Silva C, Labadie K, Alberti A, Aury JM, Louis A, Dehais P, Bardou P, Montfort J, Klopp C, Cabau C, Gaspin C, Thorgaard GH, Boussaha M, Quillet E, Guyomard R, Galiana D, Bobe J, Volff JN, Genet C, Wincker P, Jaillon $\mathbf{O}$, Roest Crollius $\mathbf{H}$, and Guiguen $\mathbf{Y}$. The rainbow trout genome provides novel insights into evolution after whole-genome duplication in vertebrates. Nat Commun 5: 3657, 2014.

4. Brawand D, Wagner CE, Li YI, Malinsky M, Keller I, Fan S, Simakov O, Ng AY, Lim ZW, Bezault E, Turner-Maier J, Johnson J, Alcazar R, Noh HJ, Russell P, Aken B, Alfoldi J, Amemiya C, Azzouzi N, Baroiller JF, BarloyHubler F, Berlin A, Bloomquist R, Carleton KL, Conte MA, D'Cotta H, Eshel O, Gaffney L, Galibert F, Gante HF, Gnerre S, Greuter L, Guyon R, Haddad NS, Haerty W, Harris RM, Hofmann HA, Hourlier T, Hulata G, Jaffe DB, Lara M, Lee AP, MacCallum I, Mwaiko S, Nikaido M, Nishihara H, Ozouf-Costaz C, Penman DJ, Przybylski D, Rakotomanga M, Renn SC, Ribeiro FJ, Ron M, Salzburger W, Sanchez-Pulido L, Santos ME, Searle S, Sharpe T, Swofford R, Tan FJ, Williams L, Young S, Yin S, Okada N, Kocher TD, Miska EA, Lander ES, Venkatesh B, Fernald RD, Meyer A, Ponting CP, Streelman JT, LindbladToh K, Seehausen O, and Di Palma F. The genomic substrate for adaptive radiation in African cichlid fish. Nature 513: 375-381, 2014.

5. Cheng W, Guo L, Zhang Z, Soo HM, Wen C, Wu W, and Peng J. HNF factors form a network to regulate liver-enriched genes in zebrafish. Dev Biol 294: 482-496, 2006.

6. Clore JN, Stillman J, and Sugerman H. Glucose-6-phosphatase flux in vitro is increased in type 2 diabetes. Diabetes 49: 969-974, 2000. 
7. Cowey CB, Cooke DJ, Matty AJ, and Adron JW. Effects of quantity and quality of dietary protein on certain enzyme activities in rainbow trout. $J$ Nutr 111: 336-345, 1981.

8. del sol Novoa M, Capilla E, Rojas P, Baro J, Gutierrez J, and Navarro I. Glucagon and insulin response to dietary carbohydrate in rainbow trout (Oncorhynchus mykiss). Gen Comp Endocrinol 139: 48-54, 2004.

9. Edgar RC. MUSCLE: multiple sequence alignment with high accuracy and high throughput. Nucleic Acids Res 32: 1792-1797, 2004.

10. French CJ, Mommsen TP, and Hochachka PW. Amino acid utilisation in isolated hepatocytes from rainbow trout. Eur J Biochem 113: 311-317, 1981.

11. Gautier A, Le Gac F, and Lareyre JJ. The gsdf gene locus harbors evolutionary conserved and clustered genes preferentially expressed in fish previtellogenic oocytes. Gene 472: 7-17, 2011.

12. Geurden I, Mennigen J, Plagnes-Juan E, Veron V, Cerezo T, Mazurais D, Zambonino-Infante J, Gatesoupe J, Skiba-Cassy S, and Panserat S. High or low dietary carbohydrate:protein ratios during first-feeding affect glucose metabolism and intestinal microbiota in juvenile rainbow trout. J Exp Biol 217: 3396-3406, 2014.

13. Gizak A, Sok AJ, Lipinska A, Zarzycki M, Rakus D, and Dzugaj A. A comparative study on the sensitivity of Cyprinus carpio muscle and liver FBPase toward AMP and calcium. Comp Biochem Physiol B Biochem Mol Biol 162: 51-55, 2012.

14. Hahn MW. Distinguishing among evolutionary models for the maintenance of gene duplicates. J Hered 100: 605-617, 2009.

15. Hanson RW, and Patel YM. Phosphoenolpyruvate carboxykinase (GTP): the gene and the enzyme. Adv Enzymol Relat Areas Mol Biol 69: 203-281, 1994.

16. Hanson RW, and Reshef $\mathbf{L}$. Regulation of phosphoenolpyruvate carboxykinase (GTP) gene expression. Annu Rev Biochem 66: 581-611, 1997.

17. Hilton JW, and Atkinson JL. Response of rainbow trout (Salmo gairdneri) to increased levels of available carbohydrate in practical trout diets. Br J Nutr 47: 597$607,1982$.

18. Kienzle E. Effect of carbohydrates on digestion in the cat. J Nutr 124: 2568S2571S, 1994.

19. Kirchner S, Kaushik S, and Panserat S. Effect of partial substitution of dietary protein by a single gluconeogenic dispensable amino acid on hepatic glucose metabolism in rainbow trout (Oncorhynchus mykiss). Comp Biochem Physiol A Mol Integr Physiol 134: 337-347, 2003.

20. Kirchner S, Panserat S, Lim PL, Kaushik S, and Ferraris RP. The role of hepatic, renal and intestinal gluconeogenic enzymes in glucose homeostasis of juvenile rainbow trout. J Comp Physiol B 178: 429-438, 2008.

21. Kondrashov FA, and Kondrashov AS. Role of selection in fixation of gene duplications. $J$ Theor Biol 239: 141-151, 2006.

22. Krasnov A, Teerijoki H, and Molsa H. Rainbow trout (Onchorhynchus mykiss) hepatic glucose transporter. Biochim Biophys Acta 1520: 174-178, 2001.

23. Langham RJ, Walsh J, Dunn M, Ko C, Goff SA, and Freeling M. Genomic duplication, fractionation and the origin of regulatory novelty. Genetics 166 : 935-945, 2004.

24. Macqueen DJ, and Johnston IA. A well-constrained estimate for the timing of the salmonid whole genome duplication reveals major decoupling from species diversification. Proc Biol Sci 281: 20132881, 2014. 

Benedetti A. Multiple roles of glucose-6-phosphatases in pathophysiology: state of the art and future trends. Biochim Biophys Acta 1830: 2608-2618, 2013.

26. Meton I, Caseras A, Fernandez F, and Baanante IV. Molecular cloning of hepatic glucose-6-phosphatase catalytic subunit from gilthead sea bream (Sparus aurata): response of its mRNA levels and glucokinase expression to refeeding and diet composition. Comp Biochem Physiol B Biochem Mol Biol 138: 145-153, 2004.

27. Mommsen TP, and E. P. Insulin in fishes and agnathans history structure and metabolic regulation. Rev Aqua Sci 4: 225-259, 1991.

28. Panserat S, Kolditz C, Richard N, Plagnes-Juan E, Piumi F, Esquerre D, Medale F, Corraze G, and Kaushik S. Hepatic gene expression profiles in juvenile rainbow trout (Oncorhynchus mykiss) fed fishmeal or fish oil-free diets. Br J Nutr 100: 953-967, 2008.

29. Panserat S, Medale F, Blin C, Breque J, Vachot C, Plagnes-Juan E, Gomes E, Krishnamoorthy R, and Kaushik S. Hepatic glucokinase is induced by dietary carbohydrates in rainbow trout, gilthead seabream, and common carp. Am J Physiol Regul Integr Comp Physiol 278: R1164-1170, 2000.

30. Panserat S, Medale F, Breque J, Plagnes-Juan E, and Kaushik S. Lack of significant long-term effect of dietary carbohydrates on hepatic glucose-6phosphatase expression in rainbow trout (Oncorhynchus mykiss). $J$ Nutr Biochem 11: 22-29, 2000.

31. Panserat S, Plagnes-Juan E, Breque J, and Kaushik S. Hepatic phosphoenolpyruvate carboxykinase gene expression is not repressed by dietary carbohydrates in rainbow trout (Oncorhynchus mykiss). J Exp Biol 204: 359-365, 2001.

32. Panserat S, Plagnes-Juan E, and Kaushik S. Nutritional regulation and tissue specificity of gene expression for proteins involved in hepatic glucose metabolism in rainbow trout (Oncorhynchus mykiss). J Exp Biol 204: 2351-2360, 2001.

33. Panserat S, Rideau N, and Polakof S. Nutritional regulation of glucokinase: a cross-species story. Nutr Res Rev 27: 21-47, 2014.

34. Panserat S, Skiba-Cassy S, Seiliez I, Lansard M, Plagnes-Juan E, Vachot C, Aguirre P, Larroquet L, Chavernac G, Medale F, Corraze G, Kaushik S, and Moon TW. Metformin improves postprandial glucose homeostasis in rainbow trout fed dietary carbohydrates: a link with the induction of hepatic lipogenic capacities? Am J Physiol Regul Integr Comp Physiol 297: R707-715, 2009.

35. Pereira C. VMM, Moon T.W. In vitro hepatocyte metabolism of alanine and glucose and the response to insulin in fed and fasted rainbow trout. The journal of experimental zoology 271: 425-431, 1995.

36. Pfaffl MW. A new mathematical model for relative quantification in real-time RT-PCR. Nucleic Acids Res 29: e45, 2001.

37. Planas JV, Capilla E, and Gutierrez J. Molecular identification of a glucose transporter from fish muscle. FEBS Lett 481: 266-270, 2000.

38. Polakof S, Mommsen TP, and Soengas JL. Glucosensing and glucose homeostasis: from fish to mammals. Comp Biochem Physiol B Biochem Mol Biol 160: 123-149, 2011.

39. Polakof S, Moon TW, Aguirre P, Skiba-Cassy S, and Panserat S. Effects of insulin infusion on glucose homeostasis and glucose metabolism in rainbow trout fed a high-carbohydrate diet. J Exp Biol 213: 4151-4157, 2010. 
641

642

643

644

645

646

647

648

649

650

651

652

653

654

655

656

657

658

659

660

661

662

663

664

665

666

667

668

669

670

671

672

673

674

675

676

677

678

679

680

681

682

683

684

685

686

687

688

689

690

40. Polakof S, Moon TW, Aguirre P, Skiba-Cassy S, and Panserat S. Glucose homeostasis in rainbow trout fed a high-carbohydrate diet: metformin and insulin interact in a tissue-dependent manner. Am J Physiol Regul Integr Comp Physiol 300: R166-174, 2011.

41. Polakof S, Panserat S, Soengas JL, and Moon TW. Glucose metabolism in fish: a review. J Comp Physiol B 182: 1015-1045, 2012.

42. Polakof S, Skiba-Cassy S, and Panserat S. Glucose homeostasis is impaired by a paradoxical interaction between metformin and insulin in carnivorous rainbow trout. Am J Physiol Regul Integr Comp Physiol 297: R1769-1776, 2009.

43. Qian W, and Zhang J. Gene dosage and gene duplicability. Genetics 179: 2319-2324, 2008.

44. Rauch GJ, Lyons, D.A., Middendorf, I., Friedlander, B., Arana, N., Reyes, T., and Talbot, W.S. Submission and Curation of Gene Expression Data ZFIN direct submission 2003.

45. Rogers QR, Morris JG, and Freedland RA. Lack of hepatic enzymatic adaptation to low and high levels of dietary protein in the adult cat. Enzyme 22: 348356, 1977.

46. Rooney DP, Neely RD, Beatty O, Bell NP, Sheridan B, Atkinson AB, Trimble ER, and Bell PM. Contribution of glucose/glucose 6-phosphate cycle activity to insulin resistance in type 2 (non-insulin-dependent) diabetes mellitus. Diabetologia 36: 106-112, 1993.

47. Sato Y, Hashiguchi Y, and Nishida M. Temporal pattern of loss/persistence of duplicate genes involved in signal transduction and metabolic pathways after teleost-specific genome duplication. BMC Evol Biol 9: 127, 2009.

48. Schermerhorn T. Normal glucose metabolism in carnivores overlaps with diabetes pathology in non-carnivores. Front Endocrinol (Lausanne) 4: 188, 2013.

49. Seiliez I, Panserat S, Lansard M, Polakof S, Plagnes-Juan E, Surget A, Dias K, Larquier M, Kaushik S, and Skiba-Cassy S. Dietary carbohydrate-toprotein ratio affects TOR signaling and metabolism-related gene expression in the liver and muscle of rainbow trout after a single meal. Am J Physiol Regul Integr Comp Physiol 300: R733-743, 2011.

50. Skiba-Cassy S, Panserat S, Larquier M, Dias K, Surget A, Plagnes-Juan E, Kaushik S, and Seiliez I. Apparent low ability of liver and muscle to adapt to variation of dietary carbohydrate:protein ratio in rainbow trout (Oncorhynchus mykiss). Br J Nutr 109: 1359-1372, 2013.

51. Sorensen PG, Petersen IM, and Sand O. Activities of carbohydrate and amino acid metabolizing enzymes from liver of mink (Mustela vison) and preliminary observations on steady state kinetics of the enzymes. Comp Biochem Physiol B Biochem Mol Biol 112: 59-64, 1995.

52. Tamura K, Peterson D, Peterson N, Stecher G, Nei M, and Kumar S. MEGA5: molecular evolutionary genetics analysis using maximum likelihood, evolutionary distance, and maximum parsimony methods. Mol Biol Evol 28: 27312739, 2011.

53. Tanaka A, Inoue A, Takeguchi A, Washizu T, Bonkobara M, and Arai T. Comparison of expression of glucokinase gene and activities of enzymes related to glucose metabolism in livers between dog and cat. Vet Res Commun 29: 477-485, 2005.

54. Teerijoki H, Krasnov A, Pitkanen TI, and Molsa H. Cloning and characterization of glucose transporter in teleost fish rainbow trout (Oncorhynchus mykiss). Biochim Biophys Acta 1494: 290-294, 2000. 
55. Tillmann H, Bernhard D, and Eschrich K. Fructose-1,6-bisphosphatase genes in animals. Gene 291: 57-66, 2002.

56. Viegas I, Rito J, Gonzalez JD, Jarak I, Carvalho RA, Meton I, Pardal MA, Baanante IV, and Jones JG. Effects of food-deprivation and refeeding on the regulation and sources of blood glucose appearance in European seabass (Dicentrarchus labrax L.). Comp Biochem Physiol A Mol Integr Physiol 166: 399-405, 2013.

57. Walton M, and Cowey CB. Gluconeogenesis by isolated hepatocytes from rainbow trout salmo gairdneri. Comparative Biochemistry \& Physiology B 62B: 7579, 1979.

58. Walton M, and Cowey CB. Gluconeogenesis from alanine and serine by trout hepatocytes: Effects of other amino acids. Biochemical Society Transactions 11: 88-89, 1983.

59. Washizu T, Tanaka A, Sako T, Washizu M, and Arai T. Comparison of the activities of enzymes related to glycolysis and gluconeogenesis in the liver of dogs and cats. Res Vet Sci 67: 205-206, 1999.

60. Xu P, Zhang X, Wang X, Li J, Liu G, Kuang Y, Xu J, Zheng X, Ren L, Wang G, Zhang Y, Huo L, Zhao Z, Cao D, Lu C, Li C, Zhou Y, Liu Z, Fan Z, Shan G, Li X, Wu S, Song L, Hou G, Jiang Y, Jeney Z, Yu D, Wang L, Shao C, Sun J, Ji P, Wang J, Li Q, Xu L, Sun F, Feng J, Wang C, Wang S, Wang B, Li Y, Zhu Y, Xue W, Zhao L, Gu Y, Lv W, Wu K, Xiao J, Wu J, Zhang Z, Yu J, and Sun $X$. Genome sequence and genetic diversity of the common carp, Cyprinus carpio. Nat Genet 46: 1212-1219, 2014.

61. Zoran DL. The carnivore connection to nutrition in cats. $J$ Am Vet Med Assoc 221: 1559-1567, 2002. 


\section{Figure captions}

728

729

730

731

732

733

734

735

736

737

738

739

740

741

742

743

744

745

746

747

748

749

750

751

752

753

Figure 1 - Phylogenetic analysis of pck1 and pck2 (A), fbp1 (B) and g6pc (C)

Phylogenetic analyses were performed using MEGA package version 5 software (52), as previously described (11). The phylogenetic trees were built using the NeighborJoining (NJ) method. The reliability of the inferred trees was estimated using the bootstrap method with 1,000 replications. Branchiostoma floridae Pck (Genbank accession XP_002593974), Oikopleura dioica Fbp (Genbank accession CBY10016) and Latimeria chalumnae G6pc (Ensembl accession ENSLACG00000022601) protein sequences were used to root trees for Pck (A), Fbp1 (B) and G6pc (C) phylogenetic analysis, respectively. All accession numbers (from Genbank, Ensembl or Genoscope databases) are specified in brackets.

Figure 2 - Conserved synteny around the $96 p c$ loci in mammals and teleosts

Data were collected using Genomicus software version 01.01, and $g 6 p c$ genes were annotated by ourselves according to our phylogenetic analysis following ZFIN Nomenclature guidelines. Black crosses indicate loss of the g6pcb2 gene in medaka, stickleback, fugu and tetraodon genomes. Ch., chromosome; sc., scaffold, cont., contig; Gp., group.

Figure 3 - Physiological confirmation of expected phenotypes depending on the nutritional status and diet

Plasma levels of glucose (A), relative abundance of glucokinase a (gcka) and glucokinase b (gckb) mRNA (B), and overall glucokinase activity (C) in fasted (white bars), fed with NoCHO (grey bars) or HighCHO (black bars) diets and re-fasted trout after NoCHO or HighCHO diet. Data are expressed as means $\pm \mathrm{SE}(\mathrm{n}=9)$. Different letters indicate significant differences between conditions $(\mathrm{P}<0.01)$.

Figure 4 - Phylogenetic analysis of gcka and gckb

Phylogenetic analyses were performed using MEGA package version 5 software (52), as previously described (11). The phylogenetic tree was built using the Neighbor- 
754 Joining $(\mathrm{NJ})$ method. The reliability of the inferred trees was estimated using the 755 bootstrap method with 1,000 replications. The Branchiostoma japonicum, (GenBank 756 ID: AGW32307) protein sequence was used to root the tree. All accession numbers 757 (from Ensembl or Genoscope databases) are specified in brackets.

Figure 5 - Relative expression of paralogous gluconeogenic genes and corresponding overall enzyme activity

761 Relative abundance of $p c k 1$ and $p c k 2$ mRNA (A), fpbp1 paralogues (B) and g6pcb

762 paralogues (C) and respective related overall enzyme activity (D) in fasted trout

763 (white bars), trout fed with the NoCHO (grey bars) or the HighCHO (black bars) diet

764 and re-fasted trout after $\mathrm{NoCHO}$ or HighCHO diet. Data are expressed as means $\pm \mathrm{SE}$

$765(\mathrm{n}=9)$. Different letters indicate significant differences between conditions $(\mathrm{P}<$ $7660.01)$

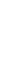
.

\section{Figure 6 - Model depicting the evolution of $g 6 p c$ genes in teleosts}

G6pc (grey) duplicated before or around teleost radiation giving rise to g6pca (green) and $g 6 p c b$ (brown). $g 6 p c b$ was then duplicated at least in the common ancestor of Euteleost, Salmonidae and Ostariophys into g6pcb1 (dark yellow) and $g 6 p c b 2$

(orange). Around salmonid radiation g6pcb1and $g 6 p c b 2$ were duplicated (g6pcb1a in light yellow, $g 6 p c b 1 b$ in brown, $g 6 p c b 2 a$ in red and $g 6 p c b 2 b$ in pink). $g 6 p c b 2$ was not maintained in the percomorph ancestor. 


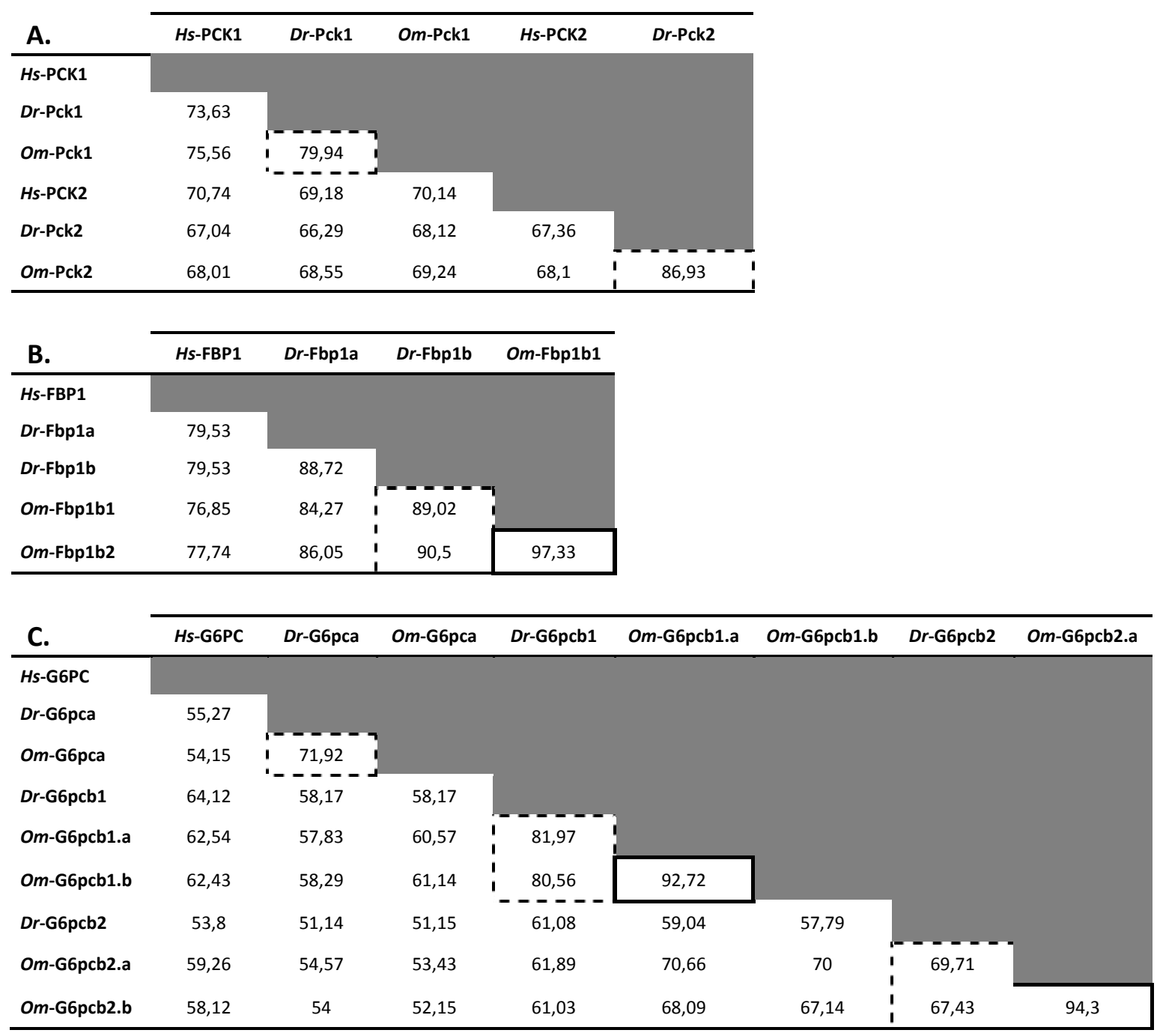

782

783 Table 1 - Matrix protein identity of phosphoenol-pyruvate carboxykinase (A),

784 fructose-1,6-bisphosphatase (B) and glucose-6-phosphatase (C) among zebrafish,

785 rainbow trout and the human

786 For accession numbers referred to phylogenetic analysis (Fig.1). Dr, Danio rerio; Hs,

787 Homo sapiens; Om, Oncorhynchus mykiss. 
Ingredients \%

793 Fish meal ${ }^{1}$ 90.85

794 Fish oil $^{2}$

$795 \mathrm{Starch}^{3}$

0

30

796 Vitamin mix $^{4}$

797 Mineral mix

1

1

798 Alginate $^{6}$

2

2

799

Proximate composition

800

Dry matter (DM, \% diet)

95.46

94.69

801 Crude protein (\% DM)

61.30

39.08

802 Crude lipid (\% DM)

804 Ash (\% DM)

${ }^{1}$ Sopropeche, Boulogne-sur-Mer, France

${ }^{2}$ fish oil; Sopropeche, Boulogne-sur-Mer, France.

${ }^{3}$ Gelatinized corn starch (Roquette, Lestrem, France)

${ }^{4}$ Supplied the following ( $\left.\mathrm{kg}-1 \mathrm{diet}\right)$ : DL-a tocopherol acetate $60 \mathrm{IU}$, sodium menadione bisulphate 5 $\mathrm{mg}$, retinyl acetate $15000 \mathrm{IU}$, DLcholecalciferol $3000 \mathrm{IU}$, thiamin $15 \mathrm{mg}$, riboflavin $30 \mathrm{mg}$, pyridoxine $15 \mathrm{mg}$, vit. B12 $0.05 \mathrm{mg}$, nicotinic acid $175 \mathrm{mg}$, folic acid $500 \mathrm{mg}$, inositol $1000 \mathrm{mg}$, biotin $2.5 \mathrm{mg}$, calcium panthotenate $50 \mathrm{mg}$, choline chloride $2000 \mathrm{mg}$.

${ }^{5}$ Supplied the following (kg-1 diet): calcium carbonate $(40 \% \mathrm{Ca}) 2.15 \mathrm{~g}$, magnesium oxide $(60 \% \mathrm{Mg})$

$8141.24 \mathrm{~g}$, ferric citrate $0.2 \mathrm{~g}$, potassium iodide (75\% I) $0.4 \mathrm{mg}$, zinc sulphate (36\% $\mathrm{Zn}) 0.4 \mathrm{~g}$, copper sulphate $(25 \% \mathrm{Cu}) 0.3 \mathrm{~g}$, manganese sulphate $(33 \% \mathrm{Mn}) 0.3 \mathrm{~g}$, dibasic calcium phosphate $(20 \% \mathrm{Ca}$, $18 \%$ P) $5 \mathrm{~g}$, cobalt sulphate $2 \mathrm{mg}$, sodium selenite $(30 \% \mathrm{Se}) 3 \mathrm{mg}$, potassium chloride $0.9 \mathrm{~g}$, Sodium 817 chloride $0.4 \mathrm{~g}$.

$818{ }^{6}$ Louis François, Marne-la-Vallée, France. used (NoCHO and HighCHO diets) in this experiment. 


\begin{tabular}{llll}
\hline Gene & Forward primer (5'-3') & Reverse primer (5'-3') & $\begin{array}{l}\text { Sigenae or Genoscope } \\
\text { Accession number }\end{array}$ \\
\hline$R S 16$ & TTTCAGGTGGCGAAACATGC' & GGGGTCTGCCATTCACCTTG & tcbk0005c.0.13_5.1.om.4 \\
\hline$g c k a$ & CTGCCCACCTACGTCTGT & GTCATGGCGTCCTCAGAGAT & GSONMG00033781001 \\
$g c k b$ & TCTGTGCTAGAGACAGCCC & CATTTTGACGCTGGACTCCT & GSONMG00012878001 \\
\hline$p c k 1$ & ACAGGGTGAGGCAGATGTAGG & CTAGTCTGTGGAGGTCTAAGGGC & GSONMG00082468001 \\
$p c k 2$ & ACAATGAGATGATGTGACTGCA & TGCTCCATCACCTACAACCT & GSONMG00059643001 \\
\hline$f b p 1 a$ & GACAGAGGACGACCCGTG & GTACTGACCGGGTCCAACAT & GSONMT00001932001 \\
$f b p 1 b 1$ & CTCTCAAGAACCTCTACAGCCT & TCAGTTCTCCCGTTCCCTTC & GSONMT00063051001 \\
$f b p 1 b 2$ & ATCAGCAGGAATAGGTCGCG & CCTCCTCCAGCACGAATCTC & GSONMT00015701001 \\
\hline$g 6 p c a$ & GATGGCTTGACGTTCTCCT & AGATCCAGGAGAGTCCTCC & GSONMG00076843001 \\
$g 6 p c b 1 . a$ & GCAAGGTCCAAAGATCAGGC & GCCAATGTGAGATGTGATGGG & GSONMG00076841001 \\
$g 6 p c b 1 . b$ & GCTACAGTGCTCTCCTTCTG & TCACCCCATAGCCCTGAAA & GSONMG00066036001 \\
$g 6 p c b 2 . a$ & ATCGGACAATACACACAGAACT & CAACTGATCTATAGCTGCTGCCT & GSONMG00013076001 \\
$g 6 p c b 2 . b$ & CCTCTGCTCTTCTGACGTAG & TGTCCATGGCTGCTCTCTAG & GSONMG00014864001 \\
\hline
\end{tabular}

830

831 Table 3 - Primer Sequences and accession numbers for qPCR analysis

832 
A.

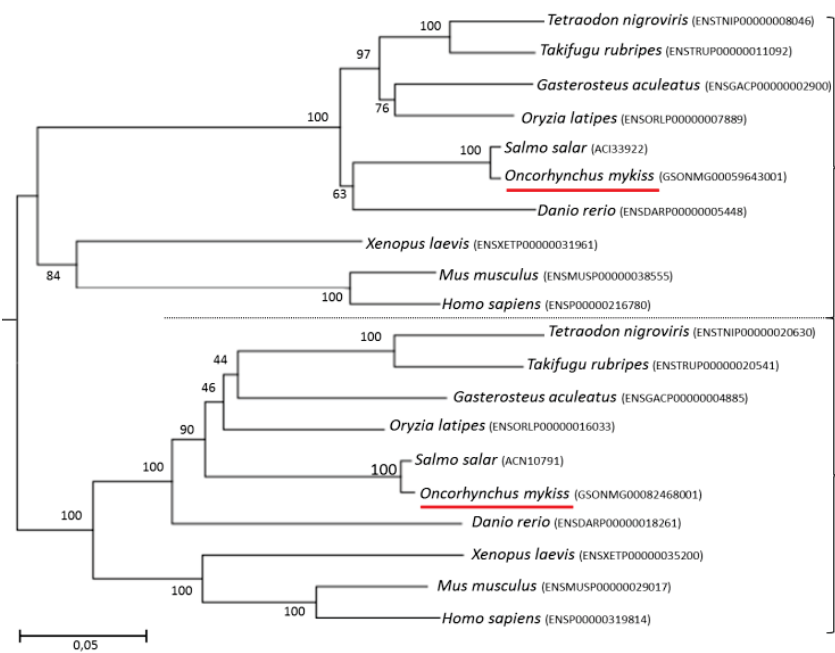

B.

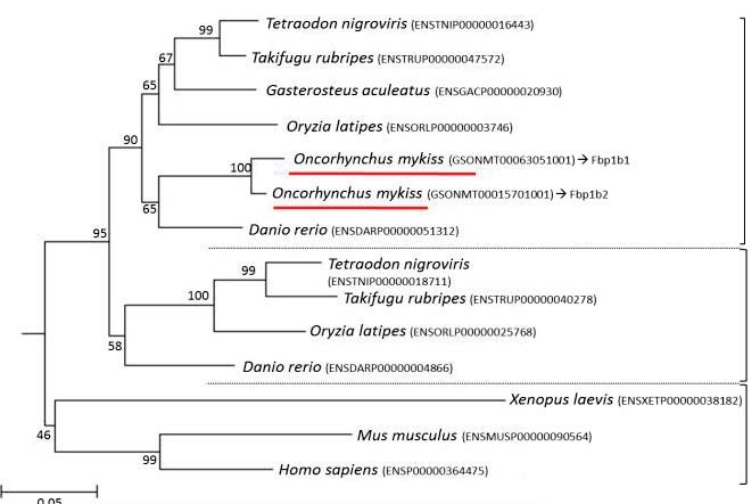

Fbp1b

Fbp1a

c.

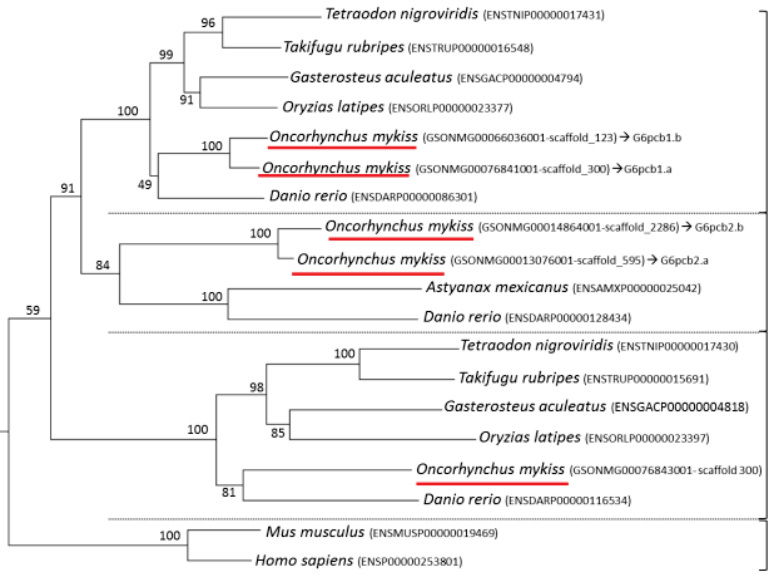

G6pcb1

G6pcb2

G6pca

G6PC

$\longdiv { 0 , 0 5 }$ 


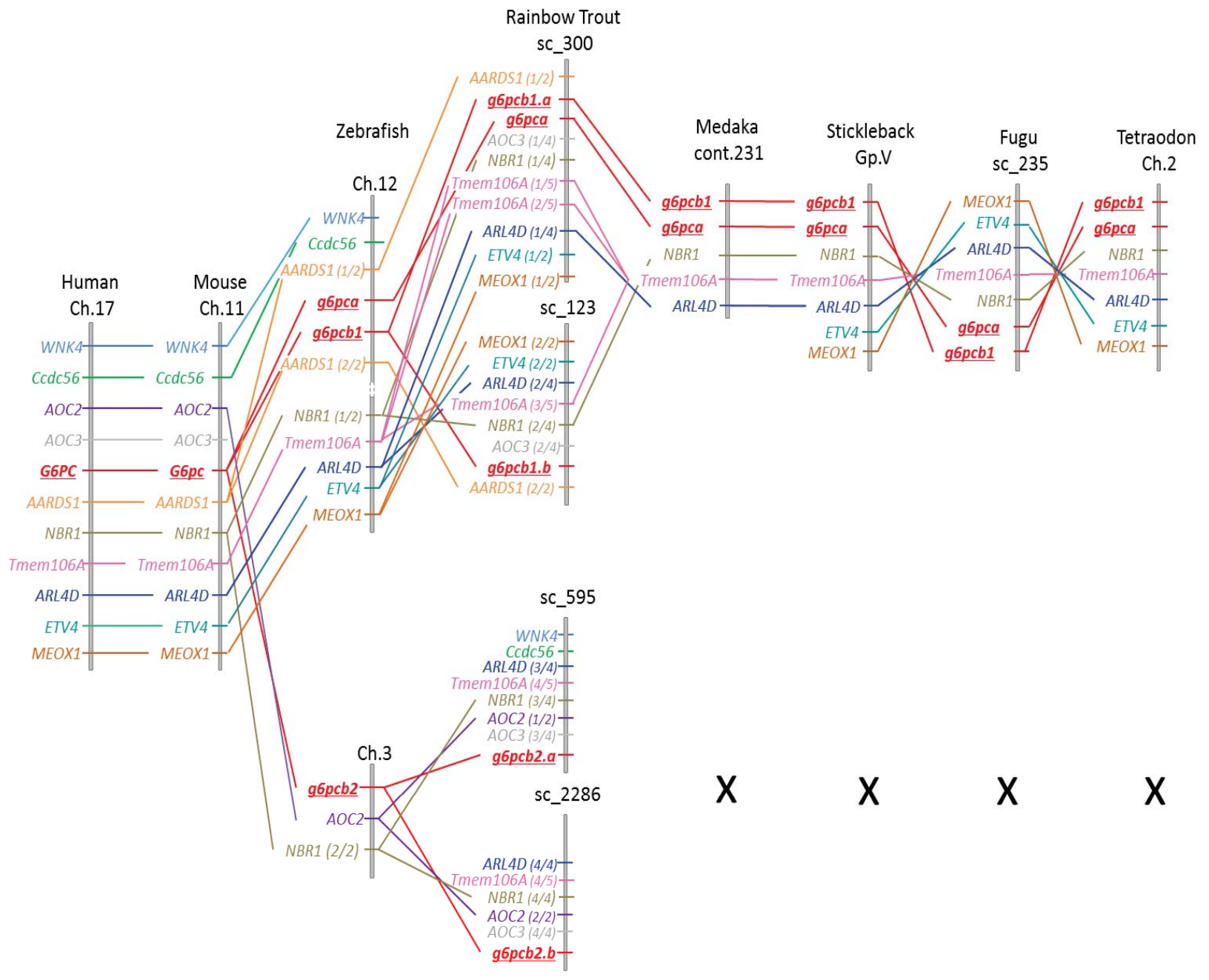



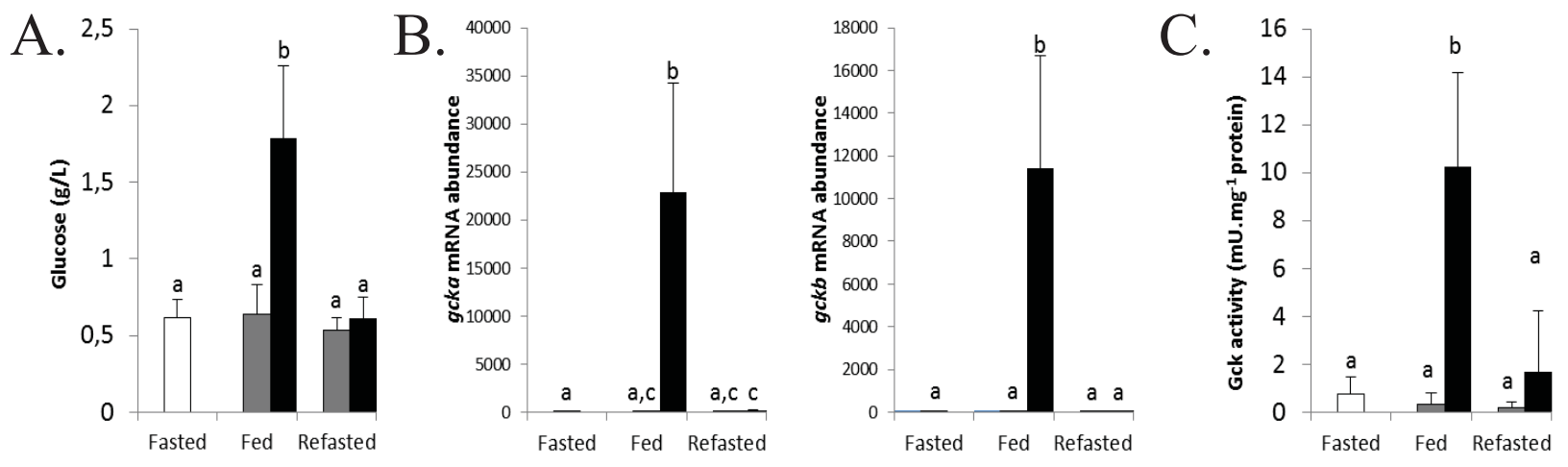


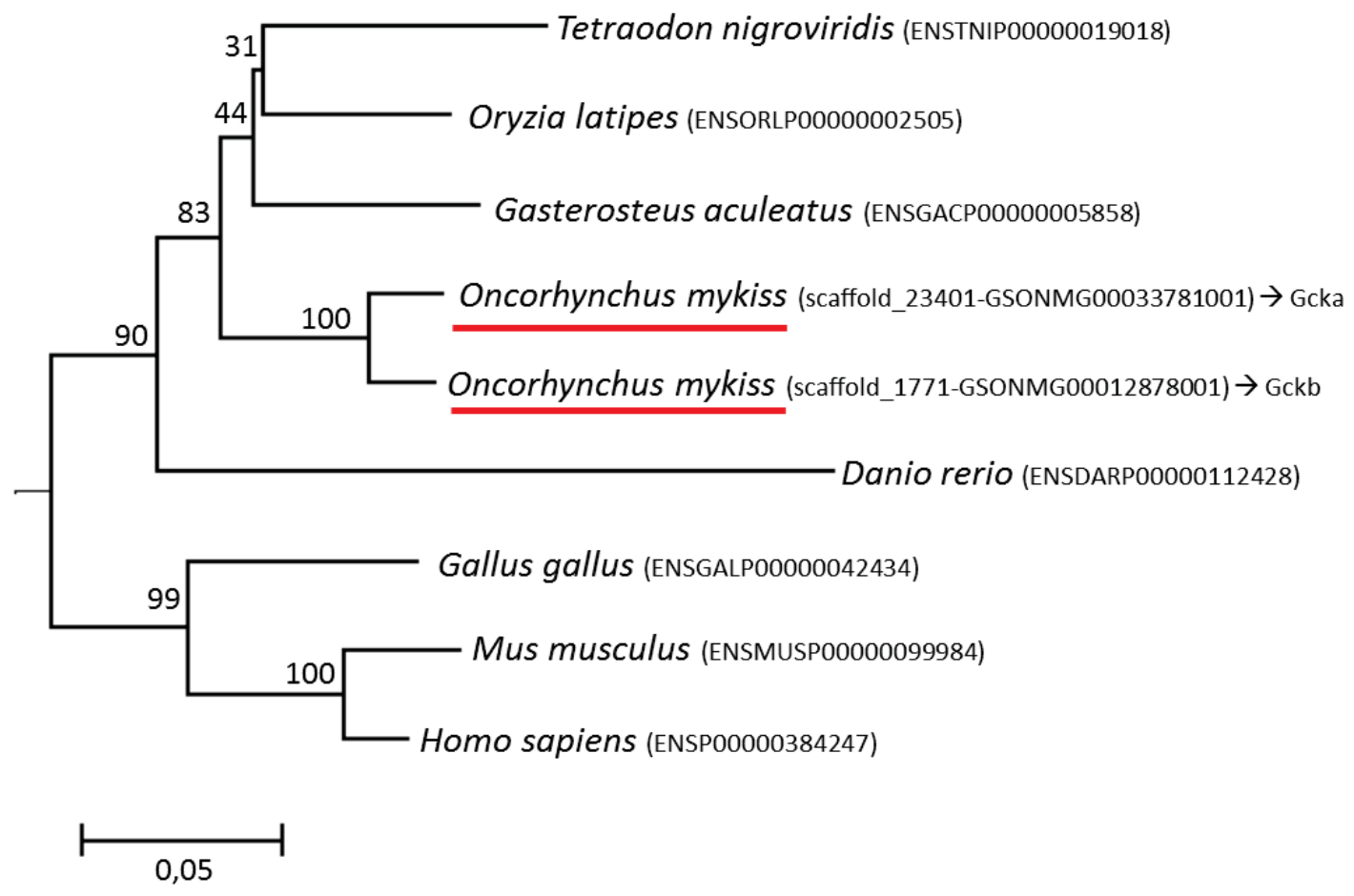



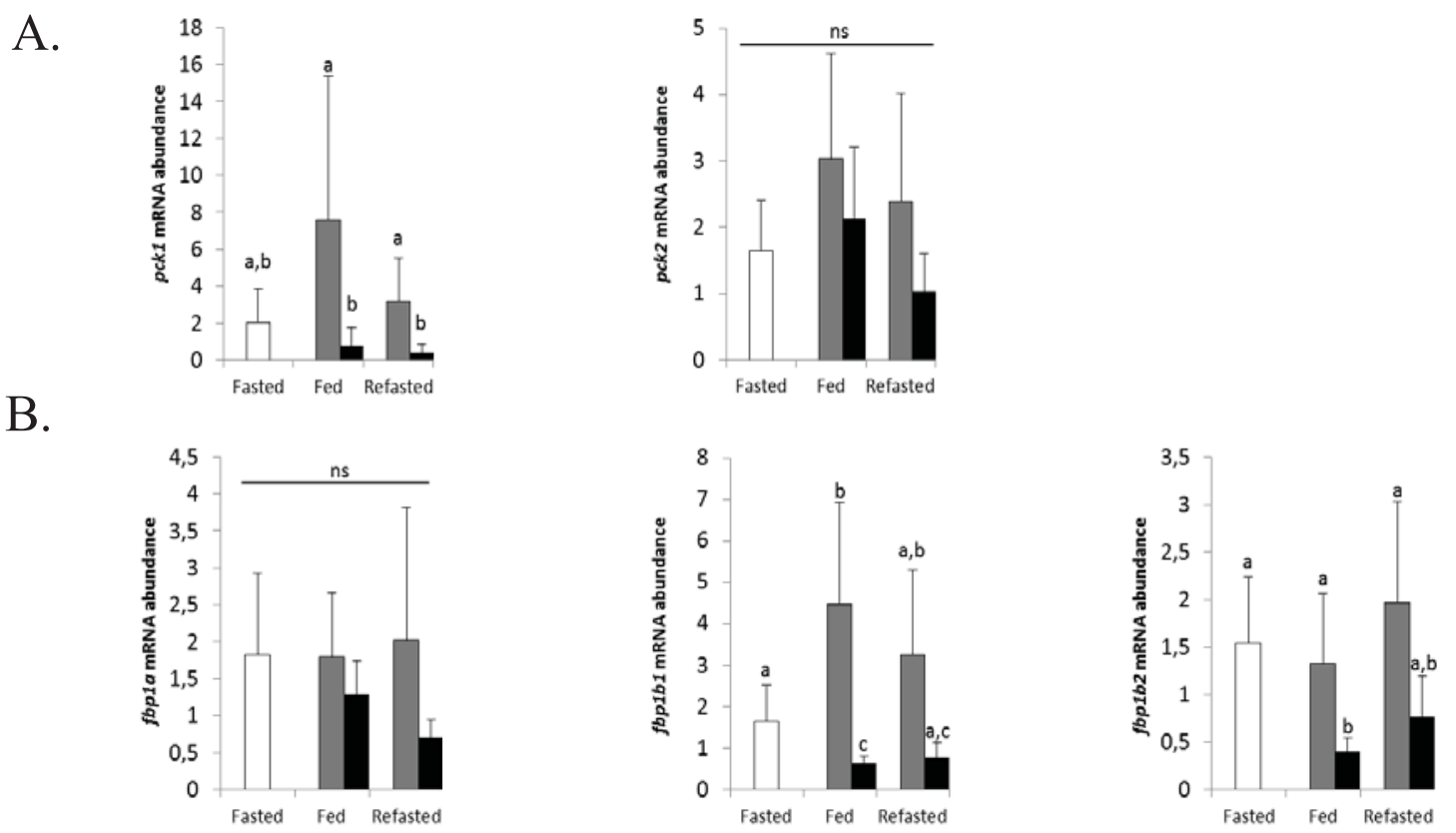

C.
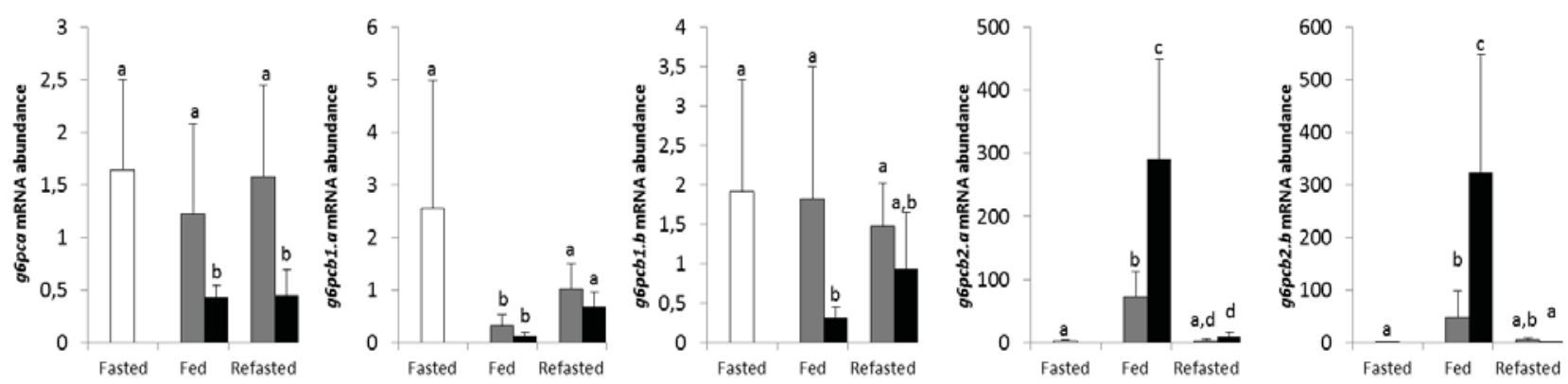

D.

a.

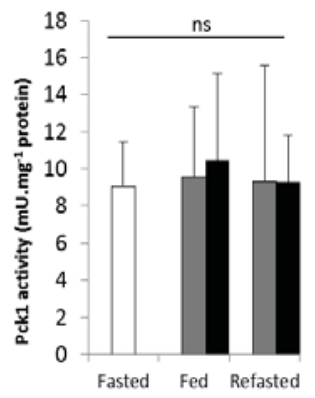

b.

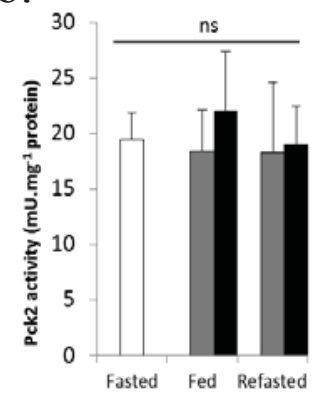

c.

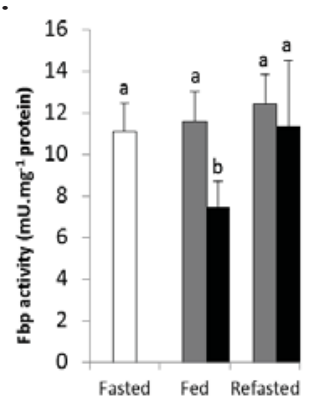

d.

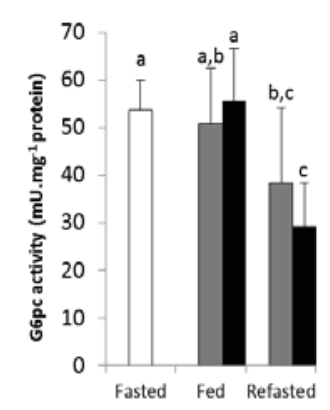


Tetrapods

Rebrafish
Rainbow trout
$\begin{gathered}\text { Salmonidae and } \\ \text { Ostariophys } \\ \text { ancestor } \\ \text { Percomorph } \\ \text { ancestor }\end{gathered}$

